\title{
JIT and Supply Chain Management: an Information Processing Perspective
}

\section{Guilherme Guedes Xavier}

Boston university

Keywords: MIS / OM interface, Just-in-time / Kanban, logistics / distribution, operations strategy.

\begin{abstract}
Recently, as part of the restructuration of the global economy, new technologies and new consumer trends have led to changes in markets around the world. Based on this restructuration, some markets have faced extremely high degrees of competition, which led to the emergence of new concepts in the productive sector. One of the most important concepts was the spread of JIT systems outside Japan in the early $80 \mathrm{~s}$. Currently, another prominent concept, named supply-chain management is emerging. In this paper, I take an information processing perspective to analyze both and conclude that; although complementary in dealing with uncertainties, both use different information processing strategies. Understanding the concepts and the relationship between them is important to their further development and diffusion among practioners and scholars' communities.
\end{abstract}




\section{PRODUÇÃO}

\section{JIT and Supply Chain Management: an Information Processing Perspective}

After WWII the American economy went through a long period of intense growth, which was strongly supported by its manufacturing sector. That scenario began to change when, following the oil crisis in the early' 70 s, global and regional markets began to shrink and American companies facing new and high levels of competition' realized that their manufacturing practices were outdated. The late' 80 s and early' 90 s were characterized by a process of recovering. In this period, updating the manufacturing process was viewed as the most important target for most of the leading industrial companies (Hayes and Wheelwright, 1984; Pisano and Hayes, 1995).

Very quickly, ideas such as reducing setup times, reducing lot sizes, increasing flexibility, products mix optimization, focused production, bottleneck management, etc. were introduced on the shop-floor (Shingo, 1981; Monden, 1981a; Skinner, 1985; Goldratt, 1986), and significant increases in productivity and quality were achieved. It is important to note that these were all concepts closely related to Just-In-Time (JIT) manufacturing strategies, introduced by the Japanese in the US in the early' 80 s (Schonberger, 1982).
However, after applying many of these concepts and having their manufacturing processes significantly improved, leading companies are realizing that some constraints are still present and a different set of gains can be achieved by integrating manufacturing strategies with distribution strategies. Companies usually face three sorts of uncertainties : supplier; process; and demand (Lee and Billington, 1992). Clearly, manufacturing strategies such as JIT production systems are very efficient in dealing with the first two kinds of uncertainties (Towill et al., 1992). However JIT systems do little to address high levels of uncertainty in demand ${ }^{2}$.

In the last several years, the literature in Operations Management and related fields has pointed out a different set of strategies to integrate different business functions within and outside companies. One of the most prominent strategies has been named supply chain management (Houlihan, 1987). Although authors in the OM field have discussed supply chain management as part of "modern inventory control theory" (Davis, 1993, p. 38), I argue that it can also be understood from an organizational design perspective.

In this paper I analyze the development of supply chain management as representing a complement of JIT manufacturing strategies (Towill et al., 1992). To accomplish that, I use Galbraith's organizational information processing theory (1973), to assess the way companies reduce uncertainty and its 


\section{PRODUÇÃO}

impact in the short and long term, through increasing information flows or reducing information needs. I conclude that, although complementary, supply chain and JIT strategies use different information processing mechanisms.

\section{Information Processing Theory}

Organizational information processing theory is concerned with the design of organizations, in particular the design of structures or mechanisms to deal with information processing requirements. Uncertainty, the central concept in Galbraith's theory, drives the need for information processing.
Galbraith (1973) proposes that when uncertainty in an organization is low, three different mechanisms can be used to resolve it: rules and procedures, hierarchies, and goals. However, when an organization faces greater uncertainty than can be handled by these three mechanisms, it must either reduce the need for information processing or it must increase information processing capacity. The decrease in the need for information processing is achieved through what Galbraith calls creation of slack and selfcontained tasks. In contrast, the increase in information processing capacity is achieved through vertical information systems ${ }^{3}$ and lateral relations. Galbraith's original model is presented in Figure 1.

What Galbraith (1974) means by

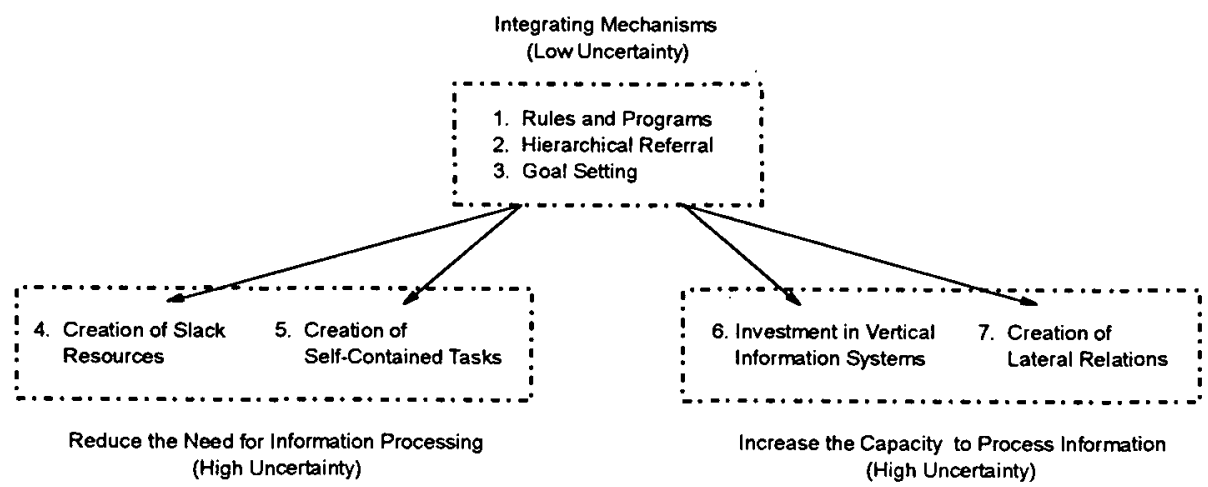

Figure 1 - Organizational Design Strategies (Galbraith, 1974, p.30) 
creation of slack resources is that as uncertainty increases, one organizational response is to increase the planning targets so fewer exceptions occur. For example, in solving job shop scheduling problems, delivery times can be quoted longer to avoid problems due to unexpected events such as machine breakdowns. The creation of self contained tasks refers to "changing the subtask groupings from resource (input) based to output based categories and giving each group the resources it needs to supply the output" (Galbraith, 1974, p.31).

According to Galbraith (1974), increasing information processing capacity can be achieved by investing in vertical information systems: creating mechanisms that lead to an increase in the flow of information in order to collect data about unexpected events (reporting or anticipating them) and provide feedback regarding the adjustment of current plans. One example is shop floor data collection mechanisms used to provide information for simulation of long term capacity problems. Finally, a company can increase its information processing capacity by creating lateral relationships. Examples of such relationships are liaison roles; task forces; teams; integrating roles; and matrix organization.

For Galbraith (1973), the uncertainty that motivates choices among information processing mechanisms is defined in general terms for the whole organization.
Tushman and Nadler (1978) pushed the analysis down to the level of the subunit and distinguished among three different sources of uncertainty: complex or nonroutine subunit tasks, unstable subunit task environments, and interdependence between subunits. For example, a manufacturing unit dealing with very sophisticated equipment, and a very sensitive process (e.g. in the semiconductor industry) might face uncertainty in the operation of this process (complex tasks), uncertainty from the environment where customer demands are constantly changing (unstable environment), and uncertainty in dealing with a procurement office that does not always understand the urgency of its requests (interdependence between subunits).

Recent additions to organizational information processing theory take the concept of uncertainty as used by Galbraith (1973) and Tushman and Nadler (1978) and break it into information requirements of two types: uncertainty and equivocality (Daft and Lengel, 1986). Uncertainty, by this new definition, is the absence of specific, needed information. For example, a manager might want to know whether sales of a product dropped last month. The question is clear and, given data on specific variables, the uncertainty would be removed.

Equivocality means there are multiple, conflicting interpretations of a situation. When equivocality is present, the precise 


\section{PRODUÇÃO}

information needed to resolve the situation is not clear. For example, the same manager might want to know why sales dropped last month. For such a question, a number of types of information might be appropriate, including the attitude and behavior of the sales force, the actions of competitors, the economic situation, trends in customer satisfaction, the weather, etc. However, the presence of information per se is not enough and further analysis and interpretation is needed.

In general, uncertainty can be reduced by a sufficient amount of information, while equivocality can be reduced by sufficiently rich information (Daft and Lengel, 1986). Certain types of information processing mechanisms, such as computerized information systems, provide large amounts of information and can thus help reduce uncertainty. However they are not as rich a source as other information processing mechanisms, such as face-to-face meetings by a continuous improvement team, and thus are not as effective in reducing equivocality.

\section{Dealing with Uncertainties in JIT}

From an economic perspective, the idea of dealing with uncertainty is directly related to the concept of productivity and efficiency in a system. In other words, understanding uncertainty and reducing its impact allows a company to achieve higher levels of productivity. However it is interesting to notice that the concept of productivity within manufacturing systems is not static and has changed over the years.

In the eighteenth century, Adam Smith argued that labor productivity would increase if jobs were split up into ever more minute-defined specialized tasks, each of which was performed by a dedicated laborer and/or machine. Over the years, new ideas were added to this principle and in the late nineteenth century, with F.W. Taylor, and in the first part of the twentieth century, with Henry Ford, an early manufacturing strategy took form. In general, the organizing principle was based on maximizing the utilization of the production structure (machinery and labor), through standardized products moving on production lines with fragmented tasks performed by specialized machinery and workers (Sayer, 1987).

From an efficiency (i.e. economic) perspective, the most important targets were to minimize the costs of setting up machines and never stop the line. To reach these targets, large batches were scheduled, inventories were held just-incase anything went wrong and quality inspections were performed after finishing the products. Sales forecasts were required to plan the production and find the optimal economic points, but the market was just seen as a constraint to achieving the optimal production levels. Manufacturing strategy was operationalized through techniques that 


\section{PRODUÇĀO}

pushed production in accordance with sales forecasts and built up inventories to minimize the individual cost of products.

This efficiency-focused manufacturing strategy had its peak in the post war period, with the profitable utilization of specialized labor available in different parts of the world. Indeed, world market factories were set up to perform integrated and complementary production processes in different parts of the globe.

Meanwhile, due to the tiny size of the Japanese market, Japanese industries could not take advantages of economies of scale (Sayer, 1987), which led to experiments with new industrial systems in the late' 40s. By the '70s, when Japanese productivity levels had overtaken Western levels, a new manufacturing strategy was formally presented to the rest of the world (Wheelwright, 1981).

Since its introduction, and especially after the success of Japanese exports around the world, the model called JustIn-Time (JIT) has been extensively studied. Moving away from basic economic principles of traditional manufacturing strategy, JIT turns a company's attention from the monitoring of cost per item to an understanding that the operating expenses of the total system need to be minimized while the saleable production is maximized. The focus has shifted to measures of Return on Capital Employed and Stock Turn Ratio (Harrison, 1987).

This idea is also presented by Mondem $(1983$, p. 3$)$, who argued that the result of a JIT system is to "provide profit increase under slow growing economy" by increasing the saleable production (the right mix, at the right number at the right time demanded by the market) and reducing costs by eliminating waste $^{5}$.

The target is the elimination of waste in all forms, particularly inventories, and a flexible production system adaptable to demand changes ${ }^{6}$. To achieve this end, the production process is organized in small batches which flow through work cells in which skilled workers perform different jobs. The JIT philosophy is demand driven, with processes being triggered only when demand exists, and for this reason it is known as a pull process (Shingo, 1981).

\section{Applying the Information Processing Perspective to JIT}

To relate operational concepts according to information processing I use a framework adapted from Monden (1983, p. 2) and Ghinato (1995, p. 176), which presents operational concepts of the JIT manufacturing strategy.

As shown in Figure 2, the first 


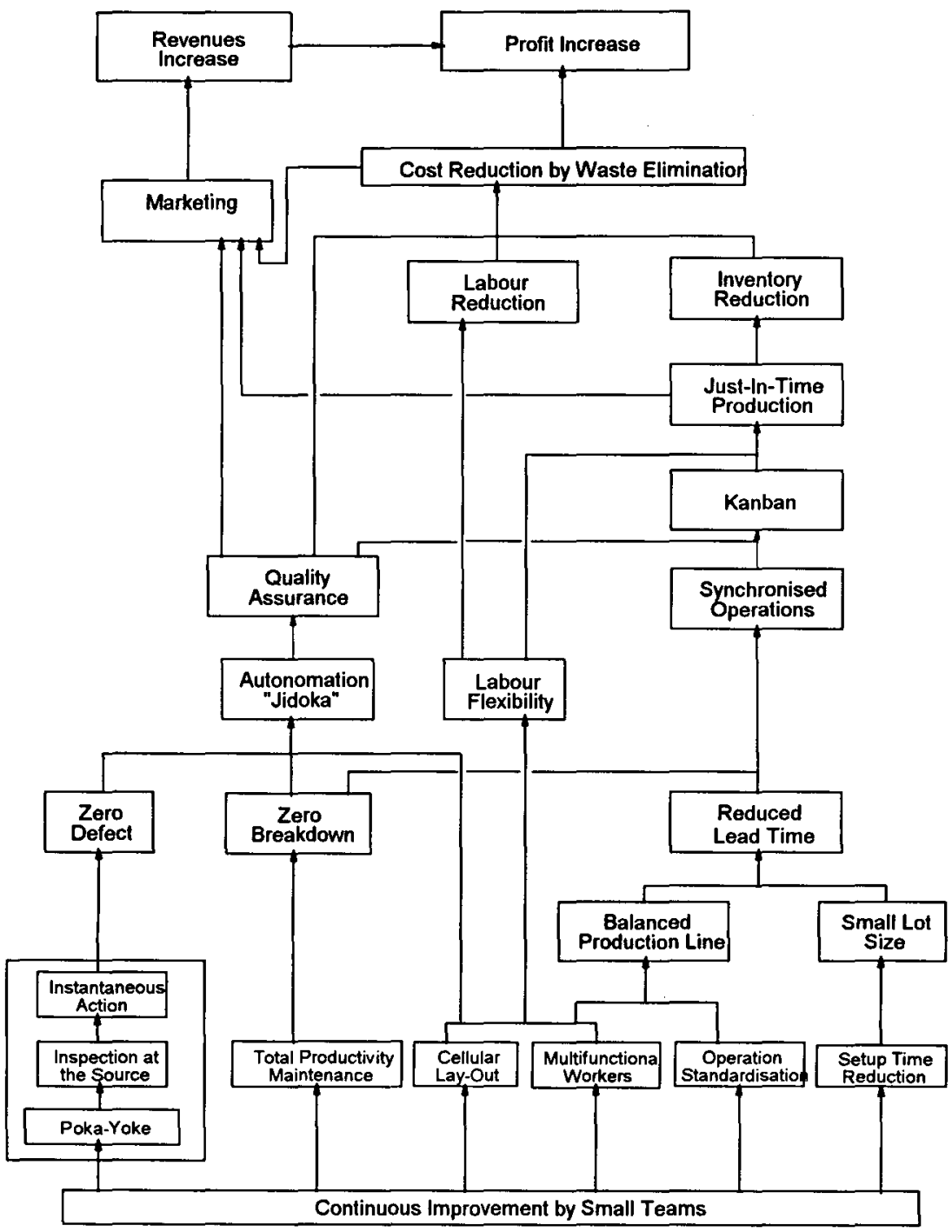

Figure 2 - Main concepts of a JIT Manufacturing strategy, adapted from Monden (1983, p.2) and Ghinato $(1995$, p.176) 


\section{PRODUÇÃO}

operational concept to be implemented in a JIT environment is continuous improvement by small groups. Some of the main activities associated with small groups in a JT environment are reducing machinery setup times, standardizing operations, working on lay-out, restructuration towards product-oriented production cells, and implementing zero defect and Total Productive Maintenance (TPM) programs. At the same time, there is a need to train workers to become multifunctional operators. Looking at these concepts and at Galbraith's model (Figure 1) we can identify the information processing strategies associated with them.

First, the establishment of small groups on the shop-floor, can be interpreted as a way to increase information processing locally and reduce the need of information processing throughout different hierarchical processes through the creation of selfcontained tasks. This is also a way to deal with equivocality. Following the same logic, we can also interpret multifunctional workers, cellular layout, and TPM programs as ways to reduce the need for information processing by the creation of self-contained tasks.

In the second JIT stage, short setup times, standardized operations, equipment arranged in a cellular layout and operated by multifunctional workers, lead to smaller lot sizes and balanced production lines. As a result, lead-time and its variability, which are a very important source of uncertainty and imbalance in manufacturing processes (Lee and Seah, 1988), are reduced. Uncertainty is also reduced by decreasing the frequency of machine downtime through TPM and by reducing the percentage of defective items through zero defect programs.

One interesting concept related to Galbraith's model is "Poka Yoke" (Monden, 1983), which means the deployment of fool-proof mechanisms in order to avoid occurrence of mistakes. These mechanisms are usually developed by workers, who apply their expertise and tacit knowledge about equipment and processes in order to reduce the number of defective items and to create a safer work environment. Therefore, although the concept of Poka Yoke is not directly related to forms of organizational design, it reduces the need for information processing required to deal with uncertainty (i.e., defective items).

Another important concept of JIT associated with the information processing perspective is "Jidoka". According to Monden (1983) Jidoka means giving workers the autonomy to stop the line whenever a problem is detected. As we saw, this is a dramatic departure from the traditional manufacturing strategy and is considered one of the bases for quality assurance in JIT environments. This worker responsability is also considered a key element for the introduction of a kanban production control system. From the organizational perspective, this can be 
interpreted as a strategy for reducing the need for processing information throughout different parts of the organization such as production, engineering, quality control, and maintenance, by creating self-contained tasks. In other words, it means changing the subtasks' groupings to an output based category and giving the group resources (i.e., control over the process) to supply outputs (i.e., quality assurance).

The introduction of kanban is also directly related to information processing within JIT systems. Traditionally production control systems tend to rely on increasing the capacity to process information as one important strategy to deal with uncertainty in manufacturing processes. A classic example is Manufacturing Resources Planning (MRP) and its associated databases which contain information about products and processes. Although some authors point out that MRP and other computerized systems such as OPT can be used to achieve a JIT environment (Hartland, 1987; Harrison, 1987), the simple but powerful communication using kanban was originally a very important part in the development of the JIT manufacturing strategy. Therefore, it seems more appropriate to use the concept of kanban in discussing JIT and information processing theory.

A kanban system per se is an information system that uses signals (usually cards) to control the flow of materials on the shop floor. The basic idea behind kanban is to shift production control to the shop floor, allowing local and quick feedback to the production process. Local and quick feedback is achieved by high levels of visibility in the process via kanban boards and other signaling mechanisms, such as lights attached to the production equipment, in order to provide information about the systems' current status' . As a result, there is a decreased need for vertical information flows (scheduler-supervisorworker) and an increase in the simplicity of the production control system. The local information is also useful to reduce problems with equivocality.

However, simplicity has its drawbacks, and a company using kanban systems loses some of its data gathering capacity. for application to other processes (e.g., product design, capacity planning, managerial accounting, etc.). In fact, this is frequently acknowledged to be one of the weaknesses of kanban systems (Hartland, 1987).

Following the model in Figure 2, once the company has implemented a JIT system and has been able to reduce uncertainty by tuning its manufacturing process, it benefits from reduced costs through waste elimination and increasing revenues through market-oriented production.

In companies applying JIT, the same concepts are transferred (taught) to their suppliers in order to achieve an integrated production (Harrison and Voss, 1990; 


\section{PRODUÇĀO}

Womack et al., 1990). External kanbans can also be used to link customer and supplier manufacturing processes. Uncertainties (product quality, deliveries, etc.) within the supply process are reduced using the same mechanisms discussed above, using the JIT systemic approach .

However, uncertainties on the market side (demand) cannot be addressed totally by improvements in the process and supply side. A complementary strategy is needed. In the next section I discuss the role of supply chain management.

\section{Dealing with Uncertainties in Supply Chain Management}

The origins of the term "supply chain management" are unclear. It seems reasonable to believe that it follows Porter's $(1980,1985)$ concept of the value chain and it was motivated by the increasing strategic role played by logistics systems in a global economy (Houlihan, 1987). According to Geoffrion and Powers (1995), the growing corporate and strategic decision-making analysis is one result of the higher levels of complexity faced by modern markets. Variables such as product differentiation, new manufacturing technologies, multisupplier environments, and increased pressure from extremely integrated and competitive markets have led firms to constantly evaluate different production and distribution alternatives according to their impact on a company's long-term performance.

Traditionally, logistic systems have been classified into three broad groups : lot sizing models, vehicle loading/routing models, and network design (locationallocation) models (Diaby and Martel, 1993). In the late' 80s and carly' 90 s a series of papers presented models integrating material, production and distribution systems, without using the supply chain management label (Eliashberg and Steinberg, 1987; Cohen and Lee, 1988; Cohen and Lee, 1989; Geofrion and Powers, 1995). However, most of these papers did not integrate fucntions system-wide ${ }^{8}$. At the same time, another set of papers presenting the same idea, but discussing systems'-wide integration were also published ( Houlihan, 1987; Lee and Billington, 1992; Towill et al., 1992; Davis, 1993). These papers introduced the supply chain management label in the operations management literature.

Following Lee and Billington (1993) we can define the supply chain as "a network of facilities that performs the functions of procurement of material, transformation of material to intermediate and finished products, and distribution of finished products to customers" ( p. 835). According to Houlihan (1987) supply chain management differs from classical materials and manufacturing control in four aspects : (a) it views the supply chain as a single entity rather than relegating fragmented responsibility for various 
segments to functional areas; (b) it is a strategic decision function; (c) it provides a different perspective on inventories, which are used as a balancing mechanism of last, not first, resort ${ }^{9}$ (d) it requires integration, not simply interface ${ }^{10}$. Houlihan sees the supply chain model as providing a "strategic balance of supply (inventory) and demand (throughput) based on firm-wide objectives and supported by a system approach that places a premium on the fast transfer and accessibility of information across functional barriers." (p. 55)

This systemic approach focusing on firm-wide objectives and on the company throughput, brings supply chain management very close to the economic perspective of a JIT system, presented in the second section of this paper. Moreover, although inventories in supply chain management are not seen as waste, but as balancing mechanisms for operational efficiency, they are still considered as the last resort. For example, supply chain management considers alternative strategies for logistics networks (Arntzen et al, 1995) and product design (Lee et. al, 1993) as more efficient ways to reduce the impact of uncertainties than the use of inventories. Even in very successful JT environments, such as Toyota's, some minimum levels of inventories are still present (Shingo, 1991); thus, the idea of inventory as a last resort is not completely incompatible with a JIT system.

On the other hand, it is interesting to notice that one of the most advanced companies in applying the concept of supply chain management - HewlettPackard (HP) - is also well known as being an early adopter of JIT strategies in its manufacturing processes and supplier channels. Davis (1993) noted that when developing its supply chain models, HP realized that the "chief culprit was demand uncertainty" and not process or supply uncertainties. The reason was because HP processes were already "welltuned" and that the "duration of process interruptions were negligible compared to the overall length of the supply chain" ( $p$. 44).

It seems reasonable, then, to interpret supply chain management as a complement to JIT systems" when a company faces high levels of demand uncertainty. However, from an information processing perspective, the mechanisms for dealing with uncertainty applied by JIT and supply chain management systems are completely different.

\section{Applying the Information Processing Perspective to Supply Chain Management}

As noted above, in supply chain management one important principle is to provide the "transfer and accessibility of information across functional barriers" (Houlihan, 1987, p. 55). One serious problem for assessing information processing strategies within supply chain management systems is the lack of a general model, such as the one presented 


\section{PRODUÇÃO}

for JIT systems. Best practices and general directions are still being developed within firms (Lee and Billington, 1995). Therefore, the discussion in this section builds on information gathered from the existing literature that presents supply chain models developed by different companies.

Based on this literature, it seems reasonable to conclude that the flow of information in supply chain management has a different operationalization than in JIT manufacturing systems. I argued above that JIT reduces the need of information processing, mostly by creating self contained tasks. On the other hand, Davis (1993) pointed out that due to its cross-functional nature and systemic approach, effective operational supply chain control requires centralized coordination of key data from different entities. Key data should be available at any point of the supply chain through integrated databases.

Further developing this idea seems clear that the goal of information processing strategy in supply chain management is to increase information processing capacity. To do that, one of the most important mechanims is vertical information systems. In a JIT manufacturing environment, results are checked locally and feedback is straight, providing opportunities for continuous improvements. In a supply chain environment, the complexity of multiechelon players makes the coordination and optimization of the system much more difficult, and mechanisms used in JIT are not appropriate anymore. According to Davis (1993, p. 36) "only analytical tools can tune the supply chain." 12

The idea of centralized information systems integrating different parts of the supply chain is confirmed by Lee and Billington (1992), who identified the requirements for effective coordination within the supply chain: (a) collection of data for documenting and tracking uncertainties; (b) creation of common metrics; (c) linkage of information systems for data integration and communication; and (d) use of information for developing efficient policies. Most of these requirements are directly associated with increasing companies' information processing capacity through more efficient vertical information systems.

Another requirement pointed out by Lee and Billington (1992) - the correct assessment of alternatives - is also related to increasing information processing, but follows a different mechanism. In fact, another information processing mechanism commonly used in developing supply chain models is the creation of lateral relations through the composition of project teams. Such a strategy was used both in the HP example provided by Lee and Billington(1995) and in the Digital example provided by Arntzen et al. (1995). According to Lee and Billington, project teams (lateral groups) have a dramatically impact in reducing 
equivocality by obtaining appropriate data and information, assessing and interpreting the analysis properly and validating the outputs. Finally, project teams are important for their positive impact on management receptivity.

\section{Conclusion}

This paper is based on models and concepts presented in the Operations Management literature about JIT and supply chain management. It looks at the relationship between these two concepts and analyzes them through an information processing perspective. Two -major conclusions can de drawn.

First, supply chain management can be interpreted as a complement to JIT manufacturing strategies in companies that have very complex manufacturing/ distribution processes (multiechelon, multiplayers, multiproduct, stochastic demand). In such contexts, uncertainties are amplified through different stages of the supply chain. Although JIT manufacturing strategies can be used to reduce uncertainties in supply and process, there are serious problems associated with uncertainty in demand. Supply chain management can be useful in reducing the impact of uncertainties from the demand side.

Second, although both JIT and supply chain management have similar economic goals, the mechanisms used for dealing with uncertainty through information processing are very different. Basically,
JIT reduces uncertainty by decreasing the need for information processing throughout the manufacturing process employing self contained tasks. In contrast, supply chain management deals with uncertainty by increasing the information processing capacity through the creation and improvement of information systems and through the creation of lateral relations.

Since conclusions were made based on theoretical discussions, future research should focus on evaluating these empirically. Understanding the relationship between JIT and supply chain management and understanding the design of the information mechanisms supporting them, are important factors for the adoption and success of manufacturing/distribution strategies within and outside firms.

Recebido em: 20/10/97

Aceito em: $15 / 04 / 98$

Publicado em: 27/07/98

\section{References}

Arntzen, B.C., Brown, G.G., Harrison, T.P. and Trafton, L.L., 1995. "Global Supply Chain Management at Digital Equipment Corporation", Interfaces, vol. 25, no. 1, 69-93.

Cohen, M.A. and Lee, H.L., 1988. "Strategic Analysis of Integrated Production-Distribution Systems: Models and Methods", Operations Research, vol. 36 , no. 2, 216-228. 


\section{PRODUÇÃO}

Cohen, M.S and Lee, H.L., 1989. "Resource Deployment Analysis of Global Manufacturing and Distribution Networks", Journal of Manufacturing and Operations Management, vol. 2, 81-104.

Cohen, M., Agrawal, N., Agrawal, V. and Raman, A., 1995. "Analysis of Distribution Strategies in the Industrial Paper and Plastics Industry", Operations Research, vol. 43, no. 1, 6-18.

Daft, R.L. and Lengel, R.H., 1986. "Organizational Information Requirements, Media Richness, and Structural Design", Management Science, vol. 32 , no. $5,554-571$

Davis, T., 1993. "Effective Supply Chain Management", Sloan Management Review, vol. 34 , no. 4 , 35-46.

Diaby, M. and Martel, A., 1993. "Dynamic Lot Sizing for Multi-Echelon Distribution Systems with Purchasing and Transportation Price Discounts", Operations Research, vol. 41, no. 1, 4859.

Eliashberg, J. and Steinberg, R., 1987. "Marketing-Production Decisions in an Industrial Channel of Distribution", Management Science, vol. 33, no. 8, 9811000.

Galbraith, J., 1973. Designing complex organizations. Reading, MA: Addison-Wesley.

Galbraith, J., 1974. “Organization
Design : An information Processing View", Interfaces, vol. 4, no. 3, 28-36

Geoffrion, A.M. and Powers, R.F., 1995. "Twenty Years of Strategic Distribution System Design: An Evolutionary Perspective", Interfaces, vol. 25 , no. 5, 105-127.

Ghinato, P., 1995. "Sistema Toyota de Produção : mais do que simplesmente Just-in-Time", Produção, vol. 5, no. 2, 169-190

Goldratt, E., 1986. The goal : A process of ongoing improvement. North River Press, New York.

Harrison, A.S. and Voss, C.A., 1990. "Issues in setting up JIT supply", International Journal of Operations \& Production Management, vol. 10, no. 2, 84-93.

Harrison, M., 1987. "OPT the future for JIT", Proceedings of the Second International Conference on Just-in-time Manufacturing, Kempston, October 20$22,147-163$

Hartland, J.R., 1987. "MRP or JIT, which is best?", Proceedings of the Second International Conference on Just-in-time Manufacturing, Kempston, October 2022, 81-91

Hayes, R. H. \& Wheelwright, S., 1984. Restoring our competitive edge: Competing through manufacturing. Wiley, New York. 


\section{PRODUÇÃO}

Houlihan, J.B., 1987. "International Supply Chain Management", International Journal of Physical Distribution and Materials Management, vol. 17, no. 2, 51-66.

Jones, D. J., 1991. "JIT \& the EOQ Model: Odd Couple No More!"., Management Accounting, vol. 72, no. 8, 54-57

Lee, H.L. and Billington, C., 1992. "Managing Supply Chain Inventory: Pitfalls and Opportunities", Sloan Management Review, vol. 33, no. 3, 6573.

Lee, H.L. and Billington, C., 1993. "Material Management in Decentralized Supply Chains", Operations Research, vol. 41 , no. $5,835-847$.

Lee, H.L. and Billington, C., 1995. "The Evolution of Supply-ChainManagement Models and Practice at Hewlett-Packard", Interfaces, vol. 25, no. 5, 42-63.

Lee, H.L., Billington, C. and Carter, B., 1995. "Hewlett-Packard Gains Control of Inventory and Service through Design for Localization", Interfaces, vol. 23, no. $4,1-11$.

Lee, L.C. and Seah, K. H. (1988). "JT and the effects of varying process and setup times", International Journal of Operations Management, vol. 8, no 1, 1935
Monden, Y., 1981a. "What Makes the Toyota Production System Really Tick?", Industrial Engineering, vol. 13, no. 1,3646

Monden, Y., 1981b. “Adaptable Kanban System Helps Toyota Maintain Just-in-Time Production. Industrial Engineering, Vol. 13, No. 5, 38-46

Monden, Y., $1981 \mathrm{c}$. "Smoothed Production Lets Toyota Adapt to Demand Changes and Reduce Inventory", Industrial Engineering, vol. 13, no. 8, 4251

Monden, Y., 1981d. "How Toyota Shortened Supply Lot Production Time; Waiting Time and Conveyance Time", Industrial Engineering, vol. 13, no. 9, 2230

Monden, Y., 1983. "Toyota Production System : Practical Approach to Production Management", Industrial Engineering and Management Press.

Pisano, P. and Hayes R. H., 1995. "Manufacturing renaissance", Harvard Business Press. Cambridge, MA.

Porter, M. E., 1980. "Competitive Strategy: Techniques for Analyzing Industries and Competitors", Free Press, New York.

Porter, M. E., 1985. "Competitive Advantage: Creating and Sustaining Superior Performance". Free Press, New York 
Ramasesh, R. V., 1993. "A Logisticsbased Inventory Model for JIT Procurement", International Journal of Operations \& Production management, vol. 12 , no $6,44-58$

Samaddar, S. and Heiko, L., 1983. "Waste elimination: The common denominator for improving operations", Industrial Management \& Data System, yol. 93, no. $8,13-19$

Sayer, A., 1987. "New Developments in Manufacturing : The Just-In-Time System", Capital\&Class, 43-72

Schonberger, R., 1982. Japanese Manufacturing Techniques, The Free Press, New York

Shingo, S., 1981: Study of Toyota production system from Industrial Engineering Viewpoint, Japan Management Association, Tokyo

Skinner, W., 1985. Manufacturing, the formidable competitive weapon. Wiley, New York.

Towill, D.R., Naim, M.M. and Wikner, J., 1992. "Industrial Dynamics Simulation: Models in the Design of Supply Chains", International Journal of Physical Distribution and Logistics Management, vol. 22, no. 5, 3-13.

Tushman, M. L., and Nadler, D. A., 1978. "Information processing as an integrating concept in organizational design", Academy of Management Review, vol. 3, 613-624.
Wheelwright, S., 1981. "Japan Where operations really are strategic", Harvard Business Review, vol. 59, 67-74.

Womack, J., Jones, D. and Roos, D., 1990. The Machine that Changed the World, Rawson Associates, New York, NY.

\section{Notes}

1. A dynamic that Houlihan $(1987, p$. 53) described as "increased competition in slower growth markets."

2. Different authors have noted that JIT systems are flexible systems in the sense that they allow quick changes in production volumes and mix, which is very important when facing uncertainty in demand. However, such flexibility enhancements are limited to a small degree of demand variability (mix and volume), estimated in the literature to be no more than $10 \%$ (Towill, 1992; Hartland, 1987).

3. Vertical information systems refer to systems providing information vertically up the hierarchy to managers responsible for all units involved.

4. Jones points out that JIT minimizes expenses by "seeking a more global optimization of the entire production/ distribution network and by avoiding local optimizations, such as economic order quantities, within subsystems that occur at the expense of the larger system. (1991, p. 55)" 
5. Samaddar, S. and Heiko, L. (1983) present six different categories of waste as being target in JIT systems: (a) waste due to overproduction; (b) due to waiting; (c) due to defects; (d) due to lack of integration; (e) due to movement/ transport; (f) processing waste.

6. As we saw before, flexibility within certain limits.

7. This is a very common technique applied by Toyota (Monden, 1983) and it is an important part of the "Jidoka" concept.

8. I am grateful to Laura Forker from Boston University for making this point

9. In other words, inventories become the "mechanism by which inevitable residual imbalances are bridge, rather than the primary tool for managing the supply chain" (Houlihan, 1987, p. 60)

10. In practice, when dealing with optimization models, this is a very hard. concept to be implemented. Ideally the whole supply-chain should be looked as a system (Towill et al., 1992) and the interaction of its parts should the analyzed at once. However, for complex systems the problem of analyzing the parts of the supply chain as a system, becomes mathematically untraceable, and current supply chain models use to optimize submodels where outputs from a submodel are used as input to the next submodel (e.g. Cohen and Lee, 1988)

11. This also seems to be the interpretation by Towill et al.; (1992, p.6) who pointed out that "the stability of an individual business depends on the design of the supply chain in which it operates every bit as much as on its own JIT performance"

12: Differently from Davis (1993), Lee and Billington (1995) and Arntzen et al. (1995), Towill et al. (1992) presented a numerical approach, based on dynamic systems simulation, instead of an analytical model to analyze the supply chain problem. However, the authors also argue favorably for the need of integrating functions within the supply chain by means of technology and organization based mechanisms, in order to increase the information processing capacity and coordination.

\section{Acknowledgements}

The author would like to thank professor Laura Forker and colleagues in the seminar of logistics at Boston University for comments provided on an earlier version of this paper. The author would also like to acknowledge the support received from the Brazilian Agency of Post-Graduate Studies - CAPES under the grant no 058-94-02 